\title{
Effects of Class Ii High-Pull Headgear Activator Using Finite Element Method: Aten Year Perspective
}

\author{
Marta Isabel Jorge ${ }^{1}$, Jorge Dias Lopes ${ }^{1}$, Maria João Ponces ${ }^{1}$ and Mário Vaz ${ }^{2}$ \\ ${ }^{1}$ Department of Orthodontics, Faculty of Dental Medicine of University of Porto, Portugal \\ ${ }^{2}$ Department of Mechanical Engineering, Faculty of Engineering of University of Porto, Portugal
}

Received: February 08, 2018; Published: February 22, 2018

*Corresponding author: Marta Isabel Jorge, Department of Orthodontics, Faculty of Dental Medicine of University of Porto, Rua Dr Manuel Pereira da Silva, 4200393 Porto, Portugal, Tel: 00351253252860; Email: martaisabeljorge@gmail.com

\section{Abstract}

The combination of an activator with a headgear is a common method used to correct hyperdivergent Class II malocclusion, improving skeletal and dental relationship, distal displacement of the maxilla, and controlling vertical eruption and upper molars distalization. The importance of studying three-dimensional effects of mechanical tension on teeth, oral structures and craniofacial complex, associated with the use of these activators, is essential to ensure the success of clinical treatments. Three-dimensional finite element method use in orthodontics is gaining high acceptance from the researchers, particularly in the use of headgear activators. This study presents a mini-review of literature studies that use three-dimensional finite element method to investigate three-dimensional effects of the mechanical tension originated by highpull headgear activators, on the treatment of hyperdivergentClass II malocclusion, in the last decade.

Using set key words and inclusion and exclusion criteria, three articles wereidentified. Both studies point out the effectiveness of finite element method in the evaluation of biomechanical effects from these activators and stand out the importance of the modeling procedure in the accuracy of the experimental results. The future research in this area will be the development of more and complementary studies including different in-vitro conditions, accompanied by clinical and/or animal studies.

Keywords: Class II malocclusion; Three-dimensional finite element method; Biomechanical effects; High-pull headgear activators

Abbreviations: 2D: 2-Dimensional; 3D: 3-Dimensional; AH: Activator Headgear; FEM: Finite Element Method; HG: Headgear

\section{Introduction}

Class II malocclusion comprises several dental and facial irregularities, namely mandibulardeficiency, maxillary excess, or combination of both. The treatment of this malocclusionsintents to correct the sagittal relationship, modify the pattern of facial growth andamend hard- and soft-tissue profile, inducing a new mandibular position in sagittal and vertical terms, which results in orthodontic and orthopedic adjustments An et al. [1-6]. In hyper divergent individuals there is a disagreement of the bone bases through an angular reference, meaning, the posterior part of the face does not develop vertically in consonance with the anterior part. This results in an architectural disharmony between the anterior and posterior portions of the facial mass, accompanied by a simultaneous maxillary alveolar hyperplasia with an excessive vertical growth of the maxilla. In these individuals the face is characteristically narrow and elongated, and there are often difficulties in nasal breathing, changes in the craniocervical posture and in the position of the hyoid bone.
The treatment can be performed in several ways, depending on the identification of the involved area (maxilla and / or mandible) and the development phase, namely, using fixed appliances, functional and/or extra-oral appliances or, if necessary, a surgical treatment An et al. [1], Cerci et al. [7], Croci [8], Manfredini et al. [9], Ramallah [10]. Functional appliances have been widely used in the treatment of Class II malocclusion, since the development of the Andresen activator in the 1930s. These devices, such as the activators of Teuscher, Van Beek and Lehman have the purpose of altering mandibular function and mandibular position to transmit forces, for the teeth and skeletal bases De Pauw \& Dermaut [11-22], Negi \& Negi, [23], Singh \& Thin [14]. The headgear (HG) appliance is an effective and common treatment for Class II malocclusions, particularly when limitation of maxillary growth and dental movement are both essential, therefore contributing to the correction of the anteroposterior difference between the maxillary and the mandibular dentitions. 
The combination of an activator with a headgear ( $\mathrm{AH})$, as for example Teusher, Herbst or Twin Force Bite Corrector is used to provide greater and increased skeletal changes than the activator alone Feizbakhsh et al. [15,16], Singh \& Thind [14]. Comparing with other techniques used to distalize molars, such as intra-oral appliances and mini-implants, headgear is a better, simpler and more effective choice.The extra-oral force is achieved with a cervical, occipital or high-pull HG, which enables the activator to correct asymmetrical Class II molar relationship, as well.Controlling the vector force with suitable outer bow length and its angulation to the occlusal plan produces different types of molar distal movements Kang et al. [17,18], Squeff et al. [19]. Nevertheless, some adverse effects, such as posterior mandibular clockwise rotation, partial restriction of anterior maxillary displacement, increased lower anterior facial height, and increased proinclination of the lower incisors are referred in some cases Cachoa \& Martin [20], Üçüncü et al. [6].

Finite Element Method (FEM) is a numerical research tool that has been used by orthodontic researchers over the last decade, to study Class II and III malocclusion, allowing the evaluation of the three-dimensional (3D) effects of mechanical tension (traction and compression) on teeth, oral structures and craniofacial complex, associated with the use of fixed appliances, functional appliances, implants, maxillary expanders, and even in surgical procedures such as corticotomy Ajmera et al. [21-23], Croci [8], Garcia et al. [24], Jain et al. [25-30]. Our interest is this review was to gather articles that use FEM to study high-pull headgear activators effects' in hyperdivergent - Class II malocclusion, due to the importance of high-pull HA used in the treatment of these orthodontic problems.

The purpose of this study was to systematically review studies that use FEM to analyze three-dimensional effects of the mechanical Table 1: Articles that matched the defined inclusion and exclusion criteria. tension, originated by high-pull HA, on teeth, oral structures and craniofacial complex of Class II patients, in the last decade.This reviewwill emphasis on the:

a) Effectsof the extraoral forces in the direction of skeletalgrowth

b) Strains induced in the sutures of the midface and the cranial base

c) Biomechanical behavior of teeth under headgear loading

d) Effectiveness of FEM studies with high-pull headgear activators

\section{Material and Methods}

A literature search was performed on Pub Med andScopus databases using the following key words: "Headgear", Facemask" and "Extraoral", crossed with "Finite element". The searches performed in "All Text"were limited to Peer reviewed articles in English, published from 2008 to 2018. Irrelevant articles were excluded by reviewing the titles and abstracts, andthe remaining studies were included by evaluating the full texts according to the selection criteria: headgear/facemask appliances and finite element method. A total of 16 studies were identified, that were then reduced to 3 after the application of the inclusion criteria "Class II" and "High-Pull headgear" and the exclusion criteria "Class III malocclusion".

\section{Results}

Table 1 shows the 3 articles that matched the inclusion and exclusion criteria. The articles are presented based on the following: reference, title, purpose, study design (theoretical, clinical, etc.) and author's main conclusions.

\begin{tabular}{|c|c|c|c|c|}
\hline Reference & Tittle & Purpose & Study design & Main Conclusions \\
\hline Ulusoy et al. [32] & $\begin{array}{l}\text { Effects of Class II activator } \\
\text { and Class II activator high- } \\
\text { pull headgear combination } \\
\text { on the mandible: A } \\
\text { 3-dimensional finite } \\
\text { element stress analysis } \\
\text { study }\end{array}$ & $\begin{array}{l}\text { To evaluate the effects of } \\
\text { the Class II activator and the } \\
\text { Class II activator high-pull } \\
\text { headgear (HG) combination } \\
\text { on the mandible }\end{array}$ & $\begin{array}{l}\text { - In-vitro study - Solid mandibular } \\
\text { model using scan images taken from } \\
\text { a dry skull of a young person - Study } \\
\text { of the stress regions on the mandible, } \\
\text { resulting from Class II activator vs. HG, } \\
\text { using 3D FEM }\end{array}$ & $\begin{array}{l}\text { Class II activator and Class II } \\
\text { activator high-pull headgear } \\
\text { cause morphologic changes } \\
\text { on the mandible, including } \\
\text { a change in the growth } \\
\text { direction by activating the } \\
\text { masticatory muscles }\end{array}$ \\
\hline Gautum & $\begin{array}{l}\text { Craniofacial displacement } \\
\text { in response to varying } \\
\text { headgear forces evaluated } \\
\text { biomechanically with finite } \\
\text { element analysis }\end{array}$ & $\begin{array}{l}\text { To evaluate the effects of } \\
\text { maxillary second and third } \\
\text { molar eruption status on } \\
\text { the distalization of first } \\
\text { molars }\end{array}$ & $\begin{array}{l}\text { - In-vitro study - Analytical model } \\
\text { using scan images taken from a dry } \\
\text { skull of a 7-year-old child - Study of } \\
\text { the response in skeletal displacements, } \\
\text { resulting from three distinct headgear } \\
\text { activators (cervical, straight-pull, and } \\
\text { high-pull), using 3D FEM }\end{array}$ & $\begin{array}{l}\text { The direction of headgear } \\
\text { force might be a critical } \\
\text { factor in determining } \\
\text { the type of facial growth } \\
\text { modification resulting from } \\
\text { orthopedic headgear therapy }\end{array}$ \\
\hline $\begin{array}{c}\text { Feizbakhsh et al. } \\
{[12]}\end{array}$ & $\begin{array}{l}\text { Stress distribution in } \\
\text { maxillary first molar } \\
\text { periodontium using straight } \\
\text { pull headgear with vertical } \\
\text { and horizontal tubes: A } \\
\text { finite element analysis }\end{array}$ & $\begin{array}{l}\text { To compare stress } \\
\text { distribution in maxillary } \\
\text { first molar periodontium } \\
\text { using straight pull headgear } \\
\text { in vertical and horizontal } \\
\text { tubes }\end{array}$ & $\begin{array}{l}\text { - In-vitro study - Analytical model } \\
\text { using scan images taken from a } \\
\text { dry skull- Study of the response in } \\
\text { maxillary first molar periodontium. } \\
\text { Resulting from headgear activators } \\
\text { with a vertical or horizontal tube, } \\
\text { using 3D FEM }\end{array}$ & $\begin{array}{l}\text { Von Mises stress is reduced } \\
\text { when the distally force is } \\
\text { applied through a vertical } \\
\text { tube in comparison to } \\
\text { conventional horizontal } \\
\text { tube. A vertical headgear } \\
\text { tube is then recommended } \\
\text { if mesiolingual movement } \\
\text { of the first molar occurs due } \\
\text { to a premature loss of the } \\
\text { second molar }\end{array}$ \\
\hline
\end{tabular}




\section{Discussion}

Ulosoy et al. [30] studied the effects of the Class II activator and the Class IIactivator high-pull headgear (HG), using a 3-dimensional (3D) finite element stress analysis. The first steps were the construction of a 3D model of the mandible (from a dry human mandible) resembling in-vivo conditions, and a 3D model of the lower part of Class II appliance and its fixationto the mandibular model. Moreover, an extraoral traction force of $350 \mathrm{~g}$ (directed from the middle of the activator to the top of the condyle) was applied to simulateClass II activator, with high-pull HG combination. Authors defined experimental conditions for the physical properties of the cortical and trabecular bone segments'and the thickness of the cortical bonesegment; and used previously established experimental data for the definition of elastic properties of the materials, 3D muscular force vectors,mechanical properties of mandibular structures, angles of the masticatory muscles, muscle forces in maximum intercuspation,muscle forces in tooth-totooth position and passive muscular forces Katona et al, Koolstra, Koolstra \& van Eijden, cit. in Ulosoy et al. [30].

FEM was then used to investigate stress regions produced by: masticatory muscles in resting position on the mandible; Class II activator on the mandible; and Class II activator high-pull HG combination on themandible. The authors also calculated Von Mises stress distributions/areas on the middle and lateral side of the mandible and the stress regions on the teeth. The authors concluded that: both activators produced higher stresses on the mandibular body than on the condylar region; the anterior medial surface of the coronoid process were the most affected regions; and the maximum stress values were obtained on the muscle attachment regions.Von Mises stress valueswere similar for both activators: $8.556 \mathrm{MPa}$, on the medial side of the coronoid process (4.787 MPa on the resting state model); and $2.856 \mathrm{MPa}$ on the distal side of the second molar (1.596 MPa on the resting state model). In this study, the authors pointed out:

a) The influence of the type and the number of elements on the accuracy of finite element analysis. If more elements are used in constructing the model, more details will be obtained;

b) The advantage of using 3D FEM over the 2D method, because it enables a more accurate simulation

c) of internal stress regions that are formed on solid materials;

d) The importance of including masticatory muscles in the experimental model.

Although other authors have reported both models to have distinct effects on the total maxillofacial complex Lv et al. [16]; Singh\& Thind, [14]; Spalj et al. [31], in the present study the authors obtained similar results for both activators. The study of Gautum et al. [32] presents the biomechanically evaluation of the displacement patterns of the facial bones, resulting from three different HG loadings, using a high-resolution FEM model. The first step was to develop an analytical model using scan images taken from a dry skull of a 7-year-old child, using sequential computed
tomography.The geometry of the surfaces was generatedthrough theassembly ofelements, linked ata finite number of nodes. Nine craniofacial systems were included into the model, as previously defined by the authors Gautum et al. [32], cit. in Gautum etl al. [32], and the mechanical properties of compact and cancellous bones in the model were defined according to the experimental data from Tanne cit in Gautum et al. [32].

After this procedure, three types of headgear traction were simulated, namely the cervical-pull, straight-pull, and high-pull HG, by applying a $1 \mathrm{~kg}$ force,posteriorly directed, in the firstmolar region. Displacements of various craniofacialstructures (Maxilla, Sphenoid bone, Nasal cavity wall, Nasal bone, Zygomatic bones, Frontal bone, Sphenoid bone, Temporal bone, and Articular fossa) were then assessed with the three types of HG and different HG loadings. The authors found out that the threeHG cause posterior dislocation of themaxilla with clockwise rotation of the palatal plane, and that all forces are effective in restricting forwardmaxillary growth. Rapid maxillary expansion was observed with all three headgear types, which can enable normal mandibular growth and clockwise rotation. Nevertheless, the results for postero-superior and distal movement of the maxilla were different for the three HG. The first movement wasmaximum for the high-pull $\mathrm{HG}$, andthe second for the straight-pull HG.This means that high-pull traction seems most effective in true restrictionof the maxillary growth vector, in other words that high-pull HGcan used efficiently in hyperdivergent Class II patients, while cervical and straight-pull HG seem more suitable for hypo divergent Class II patients.

Feizbakhsh et al. [15] developed a study which aimed to compare the stress distribution in maxillary first molars using straight pull HGin vertical and horizontal tubes using FEM. The modeling for a maxillary first molar and bone was developed using a 3D procedure from a dry skull and the 3D geometry ofsystem was scanned and digitized using specific software. With this procedure authors were able to create a model of the periodontal ligament, lamina dura, enamel, cortical and spongy bone.The final geometric model of bands and tubes was then shaped using the same software, and mechanical propertiesfor several materials were applied tothe various elements. The parts from the HG tubes were considered as homogeneous elastic solid materials, and model parts and elements were then built for each part. A $150 \mathrm{~g}$ force was then appliedat the same distance and parallel to the occlusal plan, on the hachured area. Von Misses and the main stresses distribution in the root, periodontal ligament, laminadura, spongy bone, and corticalbone, for vertical and horizontal headgear tubes, were then measured and compared.

The authors concluded that the highest and the lowest stress were in the mesiobuccal root and spongy bone, respectively, among the dental periodontium. Differently, the highest stress was in the mesiobuccal root and the lowest in the palatal root, when analyzing the roots. Also, the obtained numerical values showed a significant result considering the application of the vertical vs.the horizontal tube, having the first less tension than the second. The authors justify this result because of the "difference in the surface where the force was applied on, the method of applying force on 
the tubes and themoment of creating force" Feizbakhsh et al. [15] and the highest resistance of the horizontal tube. The authors presented some limitations in their study, such as not including any adjustment in the inner bow when comparing the HG tubes, to ease the assessment and to eliminate theinfluence of inner bow action in the tubes. As final remarks, the authors suggest the development of complementary studies, based on othermathematic models, such as for the tooth and surrounding structures. However, they highlight the importance of developing parallel clinic or animal studies.

\section{Conclusion}

The main conclusions from this small bibliographic review were:

a) All three studies (Elusory et al., 2008; Gautum el al. [32]; Feizbakhsh et al. [15] point out the importance of 3D FEM in the evaluation of biomechanical components such as displacements, strains, and stresses induced on teeth, oral structures and craniofacial complex, by headgear activators.

b) The authors stress out the importance ofthe modeling procedure in the accuracy of the experimental results, indicating the influence of the type and number of elements, nodes (point where the elements are linked) and degrees of freedom used in the model. In all the three studies, the authors had the concern of using a high number of elements and nodes: Ulusoy et al. [30] refer 113,837 elements with 22,766 nodes; Gautum el al. [32] indicate 108,799 elements, 193,633 nodes and 580,899 degrees of freedom; and Feizbakhsh et al. [15] specify 85,874 elements and 22,503 nodes.

c) The use of 3D FEM in orthodontics is usually restricted to a specific structure. Ulusoy et al. [30] study was directed to the effects on the mandible; Gautum et al. [32] restricted the study to the analysis of skeletal displacements; and Feizbakhsh et al. [15] applied the study to a model of the maxillary first molar and bone.

d) The importance of accompanying FEM studies with clinical and/or animal studies Feizbakhsh et al. [15], since they will provide some verification and comparison with in-vitro studies.

It is clear for usthat research on the application of 3D FEM to the study of 3-dimensional effects of the mechanical tension, induced by high-pull headgear, on teeth, oral structures and craniofacial complex of Class II patients, provide important information about the biomechanics of the induced stresses, and must, therefore, be incentivized. This small and very objective literature review is an example of the few available studies in the topic and the need for more scientific information.

\section{References}

1. An JS, Jeon Da Mi, Jung WS, Yang H, Lim WH, Ahne SJ (2015) Influence of temporomandibular joint disc displacement on craniocervical posture and hyoid bone position. Am J Othodont Dentofac Orthop 147(1): 72-79.

2. Baccetti T, Franchi L, Mc Namara JA Jr, Tollaro I (1997) Early dentofacial features of Class II malocclusion: a longitudinal study from deciduous through the mixed dentition. Am J Othodont Dentofac Orthop 111(5): 502-509.

3. Bendeus M, Hägg U, Rabie B (2002) Growth and treatment changes in patients treated with a headgear-activator appliance. Am J Orthod Dentofacial Orthop 121(4): 376-384.

4. Hwang CJ, Sung SJ, Kim SJ (2006) Lateral cephalometric characteristics of malocclusion patients with temporomandibular joint disorder symptoms. Am J Orthod Dentofacial Orthop 129(4): 497-503.

5. Paik CH, Park HS, Ahn HW (2017) Treatment of vertical maxillary excess without open bite in a skeletal Class II hyperdivergent patient. Angle Orthodontist.

6. Üçüncü N, Türk T, Carels C (2001) Comparison of Modified Teuscher and Van Beek Functional Appliance Therapies in High-Angle Cases. J Orofacial Orthop 62(3): 224-237.

7. Cerci V, Cerci BB, Meira TM, Cerci DX, Tanaka OM (2012) Eight-year stability of a severe skeletal anterior open bite with a hyperdivergent growth pattern treated with an edgewise appliance and chin cup therapy. Am J Orthod Dentofacial Orthop 141(4): 65-74.

8. Croci SC (2015) Tensões mecânicas causadas pela distalização de molares superiores. Piracicaba. Tese [Doutoramento em Biologia BucoDental] - Faculdade de Odontologia de Piracicaba da Universidade Estadual de Campinas.

9. Manfredini D, Segù M, Arveda N, Lombardo L, Siciliani G, et al. (2015) Temporomandibular joint disorders in patients with different facial morphology. A systematic review of the literature. J Oral Maxillofac Surg 74(1): 1-23

10. Ramalhão MJFP (2009) Deslocamento Condilar nos Tipos Faciais Hiperdivergentes. Porto. Tese [Doutoramento em Ortodontia] Faculdade de Medicina Dentária da Universidade do Porto.

11. De Pauw GAM, Dermaut LR (2006) A Modified Teuscher Activator. Semin Orthod 12(1): 34-40.

12. De Souza MM, de Freitas TM, Stuani, AS, Stuani AS, Stuani MBS (2005) Uso do aparelho de Thurow no tratamento da má oclusão esquelética de Classe II. R Dental Press Ortodon Ortop Facial 10(4): 76-87.

13. Negi N, Negi KS (2014) Skeletal Class II correction by activator-headgear combination. SRM J Res Dent Sci 5(2): 131-133.

14. Singh GD, Thind BS (2003) Effects of the headgearactivator Teuscher appliance in the treatment of Class II division 1 malocclusion: a geometric morphometric study. Orthod Craniofacial Res 6(2): 88-95.

15. Feizbakhsh M, Kadkhodaei M, Zandian D, Hosseinpour Z (2017) Stress distribution in maxillary first molar periodontium using straight pull headgear with vertical and horizontal tubes: A finite element analysis. Dent Res J (Isfahan) 14(2): 117-124.

16. Lv Y, Yan B, Wang L (2012) Two-phase treatment of skeletal Class II malocclusion with the combination of the Twin-block appliance and high-pull headgear. Am J Orthod Dentofacial. Orthop 142(2): 246-255.

17. Kang JM, Park JH, Bayome M, Oh M, Park CO, et al. (2016) A threedimensional finite element analysis of molar distalization with a palatal plate, pendulum, and headgear according to molar eruption stage. Korean J Orthod 46(5): 290-300.

18. Maruo IT, Maruo H, Saga AY, de Oliveira DD, Argenta MA, et al. (2016) Tridimensional finite element analysis of teeth movement induced by different headgear forces. Progress in Orthodontics 17-18: 1-9.

19. Squeff LR, Ruellas ACO, Penedo ND, Elias CN, Sant'anna EF, et al. (2009) Asymmetric headgear for differential molar movement: a study using finite element analysis. J Ortho 36(3): 145-151.

20. Cachoa A, Martin C (2007) Kinesiographic and sonographic changes in young Class II patients treated with functional Appliances. Am J Orthod Dentofacial Orthop 131(2):196-201. 
21. Ajmera DH, Singh P, Wang C, Song J, Xiao SS, et al. (2017) Analysis of dentoalveolar structures with novel corticotomy-facilitated mandibular expansion: A 3-dimensional finite element study. Am J Orthod Dentofacial Orthop 151(4): 767-778.

22. Ammar HH, Ngan P, Crout RJ, Mucino VH, Mukdadid OM (2011) Threedimensional modeling and finite element analysis in treatment planning for orthodontic tooth movement. Am J Orthod Dentofacial Orthop 139(1): 59-71.

23. Chaudhry A, Sidhu MS, Chaudhary G, Grover S, Chaudhry N, et al. (2015) Evaluation of stress changes in the mandible with a fixed functional appliance: A finite element study. J Orthod Dentofacial Orthop 147(2): 226-234.

24. Garcia VJ, Comesana R, Kasem K, Usrtell Torrent JM, Badaoui A, et al. (2015) Short-term effects of strain produced on a split palatal screwtype hyrax appliance after rapid maxillary expansion: A clinical trial. J Orthod Dentofacial Orthop 148(6): 990-998.

25. Jain V, Shyagali TR, Kambalyal P, Rajpara Y, Doshi J (2017) Comparison and evaluation of stresses generated by rapid maxillary expansion and the implant-supported rapid maxillary expansion on the craniofacial structures using finite element method of stress analysis. Prog Orthod 18(1): $1-12$.

26. Jasmine IF, Yezdani AA, Tajir F, Venu RM (2012) Analysis of stress in bone and microimplants during en-masse retraction of maxillary and mandibular anterior teeth with different insertion angulations: A 3-dimensional finite element analysis study. J Orthod Dentofacial Orthop 141(1): 71-80.

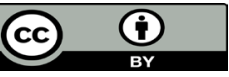

This work is licensed under Creative Commons Attribution 4.0 License

Submission Link: http://biomedres.us/submit-manuscript.php
27. Lee RJ, Moon W, Hong C (2017) Effects of monocortical and bicortical mini-implant anchorage on bone-borne palatal expansion using finite element analysis. J Orthod Dentofacial Orthop 151(5): 887-897.

28. Park JH, Bayome M, Zahrowski JJ, Kook YA (2017) Displacement and stress distribution by different bone-borne palatal expanders with facemask: A 3-dimensional finite element analysis. Am J Orthod Dentofacial Orthop 151(1): 105-117.

29. Roberts WE, Viecilli RF, Chang C, Katona TR, Paydar NH (2015) Biology of biomechanics: Finite element analysis of a statically determinate system to rotate the occlusal plane for correction of a skeletal Class III open-bite malocclusion. Am J Orthod Dentofacial Orthop 148(6): 943-955.

30. Ulusoy C, Darendelile N (2008) Effects of Class II activator and Class II activator high-pull headgear combination on the mandible: A 3-dimensional finite element stress analysis study. Am J Orthod Dentofacial Orthop 133(4): 490.9-490.15.

31. Spalj S, Tranesen KM, Birkeland K, Katic V, Pavlic A, et al. (2017) Comparison of Activator-Headgear and Twin Block Treatment Approaches in Class II Division 1 Malocclusion. Biomed Res Int 1-9.

32. Gautam P, Valiathan A, Adhikaric R (2009) Maxillary protraction with and without maxillary expansion: A finite element analysis of sutural stresses. Maxillary protraction with and without maxillary expansion: A finite element analysis of sutural stresses. Am J Orthod Dentofacial Orthop 136(3): 361-366.

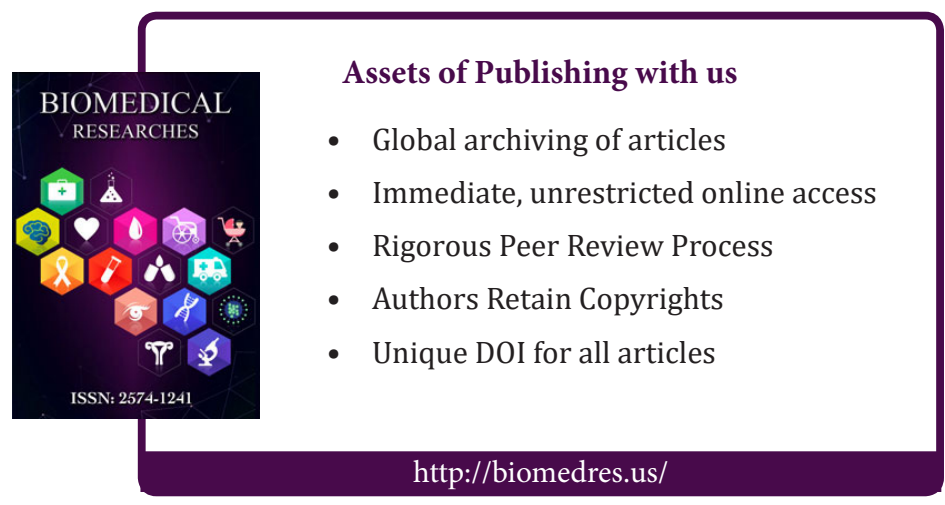

